\title{
İleri Yaşlı Hastalarda (85 yaş ve üzeri) İnkarsere İnguinal Herni Cerrahisi Deneyimlerimiz
}

\author{
Our Experiences in Incarcerated İnguinal Hernia Surgery in Super-Elderly Patients (85 Years and Above)
}

Murat Kartal

SBÜ Erzurum Bölge Eğitim ve Araștırma Hastanesi Genel Cerrahi Kliniği, Erzurum, Türkiye

Correspondence:

Murat KARTAL

SBÜ Erzurum Bölge Eğitim ve

Araştırma Hastanesi Genel Cerrahi Kliniği, Erzurum, Türkiye

e-mail:m.kartal2587@gmail.com

\section{Özet}

Eşlik eden komorbid hastalıkların fazla olması nedeniyle ileri yaş hasta grubu (85 yaş ve üzeri) ayrı bir öneme sahiptir. Çalısmamızda; kliniğimizde ileri yas hasta grubunda inkarsere inguinal herni nedeniyle acil cerrahi uygulanan olgularının sonuçların değerlendirdik. Ocak 2011-Aralık 2019 tarihleri arasında kliniğimizde inkarsere inguinal herni nedeniyle acil cerrahi uygulanan 85 yaş ve üstü 16 hastanın verileri geriye dönük olarak incelendi. Hastaların demografik özellikleri, komorbid hastalıkları, hastalara uygulanan cerrahi tedaviler, hastaların hastanede kalıs süreleri ile morbidite ve mortalite bilgileri araștırıldı. Çalışmaya dahil

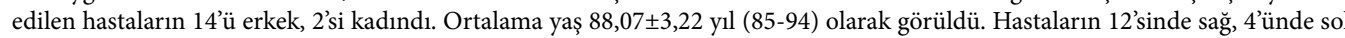
inkarsere inguinal herni mevcuttu. 11 hastada komorbid hastalık mevcut idi. 11 hastaya genel anestezi, 5 hastaya bölgesel anestezi (spinal/epidural) altında cerrahi uygulandı. 10 hastada ameliyat sırasında inkarserasyona sekonder iskemik bulgular gözlendi. İskemi mevcut olan tüm hastalara öncelikle sıcak kompres tedavisi denendi. Sıcak kompres sonrası 3 hastada barsak canllilğı gözlenirken; 7 hastanın barsak canlllığında bozukluğun devam etmesi üzerine hastalara ince bağırsak rezeksiyon anastomozu uygulandı. 9 hastaya meshli inguinal herni onarımı yapıldı (rezeksiyon oranı \%43,8). Postoperatif 3 hastada atelektazi, 2 hastada yara yeri enfeksiyonu gelişti. Hastaların ortalama hastanede kalış süresi 8,21 $\pm 3,78$ (3-15) gündü. Postoperatif dönemde 2 hasta sepsis, 1 hasta ise pulmoner emboli gelișmesi nedeniyle hastalar kaybedildi. Calıșmamızın morbidite oranı $\% 31,2$ iken mortalite oranı \%18,75 idi. İleri yaş hasta grubunda inkarserasyon nedeniyle uygulanan inguinal herni operasyonları, yüksek morbidite, mortalite ve barsak rezeksiyon oranına sahiptir. Bu durumların önüne geçmek için inguinal herni tanısı alan çok yaşlı hastalara elektif cerrahi yapılmasını önermekteyiz.

Anahtar Kelimeler: inkarserasyon, inguinal herni, mortalite, rezeksiyon, ileri yaş.

\section{Abstract}

Patients of super-elderly age ( 85 years and above) have a special importance because of comorbid diseases. In our study; we evaluated the results of emergency inguinal hernia surgeries performed in the super-elderly age group due to incarceration in our clinic. The data of 16 patients over the age of 85 who underwent emergency surgery for incarcerated inguinal hernia in our clinic between January 2011 and December 2019 were retrospectively analyzed. The demographic characteristics of the patients, comorbid diseases, types of surgical treatment, hospital stay of the patients, morbidity and mortality data were searched. 14 of the patients were male and 2 were female. Mean age of the patients was $88,07 \pm 3,22$ years (85-94). Twelve of the patients had a right and 4 had a left incarcerated inguinal hernia. 11 patients had comorbid diseases. 11 patients underwent general anesthesia, 5 patients underwent hernia surgery under regional (spinal / epidural) anesthesia. Ischemic findings secondary to incarceration were observed in 10 patients during surgery. Hot compress therapy was first tried in all patients with ischemia. While bowel vitality was observed in 3 patients after hot compress; small intestine resection anastomosis was performed in 7 patients due to deterioration of intestinal viability. Inguinal hernia repair with prosthetic material was performed in 9 patients (resection rate $43.8 \%$ ). Postoperatively, 3 patients developed atelectasis and 2 patients developed wound infection. The average hospital stay of the patients was $8,21 \pm 3,78$ days. In the postoperative period, 2 patients died due to sepsis and 1 patient due to pulmonary embolism. The morbidity rate of our study was $31.2 \%$, while the mortality rate was $18.75 \%$. In the super-elderly group, emergency inguinal hernia operations due to incarceration have high morbidity, mortality and intestinal resection rates. In order to prevent these situations, we recommend performing elective surgery to super-elderly patients with inguinal hernia.

Keywords: Incarceration, inguinal hernia, mortality, resection, super-elderly.

Received 09.04.2021 Accepted 17.05.2021 Online published 18.05.2021 


\section{Giriş}

Sağlık alanındaki gelişmeler, sağlık hizmetinin ulaşılabilirliği ve küresel çapta sağlık hizmet sunumdaki iyileşme sayesinde, ortalama yaşam sürelerinde ve yaşlı nüfus oranında artış görülmektedir. Ülkemizde 2020 itibariyle toplam nüfusun \%9,51'ini 65 yaş üzeri ve $\% 0,8$ 'ini 85 yaş üzeri popülasyon oluşturmaktadır (1).

Yaşam sürelerinin uzaması yaşlılık tanımlamalarını da değiştirmiş ve Dünya Sağlık Örgütü'ne (DSÖ) göre yaşl11ık üç alt gruba ayrılarak 65-74 yaş arası erken yaşl1lık, 75-84 yaş arası yaşl1lık, 85 yaş ve üzeri ise ileri yaşlılık olarak tanımlanmıştır (2). 65 yaş ve üzeri hasta popülasyonunda hem yaşa bağlı karın duvarındaki destek dokusunun zayıflaması hem de eşlik eden komorbid durumlardan dolayı artan karın içi basınca bağlı olarak inguinal herniler genç nüfusa oranla daha sık görülmektedir (3). Ayrıca 65 yaş ve üzeri hastalarda uygulanan anestezi ve cerrahi işleme bağlı morbidite ve mortalite oranları da artmaktadır (4). $\mathrm{Bu}$ nedenle inguinal herni tanısı alan 65 yaş ve üzeri hastalarda cerrahi tedavi; asemptomatik veya hafif semptomları olan hastalarda ertelenme eğilimindedir (5). Acil olarak inguinal herni tamirine ihtiyaç duyulduğunda morbidite ve mortalite oranları da yükselmektedir (4).

Yapmış olduğumuz çalışmada, yaşlılık grupları içerisinde bir alt grup olarak bulunan ileri yaşlı hasta grubunda ( 85 yaş ve üzeri) inkarsere inguinal herni nedeniyle acil cerrahi uyguladığımız hastaların tedavi sonuçlarını değerlendirdik.

\section{Gereç ve yöntem}

Etik kurul onay1 alındıktan sonra (Erzurum Bölge Eğitim ve Araştırma Hastanesi Noninvaziv Klinik Araştırmalar Etik Kurulu, Erzurum, Türkiye. Karar Tarihi: 01.03.2021, Karar No: 2021/05-113) Erzurum Bölge Eğitim ve Araştırma Hastanesi Genel Cerrahi Kliniği'nde Ocak 2011-Aralık 2019 tarihleri arasında inkarsere inguinal herni tanısıyla acil olarak ameliyata alınan 85 yaş üstü 18 hastanın verileri geriye dönük olarak incelendi. Veri eksikliği olan iki hasta çalışma dışı bırakılarak 16 hasta ile çalışmaya devam edildi. Hastaların demografik özellikleri (yaş, cinsiyet), komorbid hastalıkları, American Society of Anesthesiologists (ASA) skorları, uygulanan cerrahi prosedürler, postoperatif komplikasyonlar, hastanede kalış süreleri ve mortalite durumları kaydedildi.

\section{Bulgular}

Çalışmaya dahil edilen 16 hastanın 14'ü $(\% 87,5)$ erkek, 2'si $(\% 12,5)$ kadındı. Hastaların ortalama yaşı $88,07 \pm 3,22$ yıl ( 85 94) olarak görüldü. Hastaların 12 'sinde sağ taraflı, 4'ünde ise sol taraflı inkarsere herni mevcuttu. Erkek hastaların 10'nunda indirekt inguinal herni, 4'ünde direkt inguinal herni mevcuttu. Kadın hastaların ikisinde de direkt inguinal herni mevcuttu. Üç hastanın komorbid hastalığı yoktu. Dört hastada tek komorbid hastalık, yedi hastada iki komorbid hastalık ve iki hastada üç komorbid hastalık olmak üzere toplam $13(\% 81,2)$ hastada komorbid hastalik mevcuttu. Komorbid hastalıklar 10 hastada hipertansiyon, 7 hastada diyabet, 6 hastada kronik obstrüktif akciğer hastalığ 1 (KOAH) ve 1 hastada epilepsi şeklindeydi. Dört hastada ASA skoru III, 9 hastada ASA skoru IV ve 3 hastada ASA skoru V idi. Uygulanan anestezi tipi 11 hastada genel anestezi, 5 hastada ise bölgesel (epidural/spinal anestezi) şeklindeydi. Hastaların klinik özellikleri Tablo 1'de gösterilmiştir.

Ameliyat sirasinda 10 hastada inkanserasyona sekonder iskemik bulgular gözlendi. İnkansere olan barsak segmentleri serbestleştirildikten sonra iskemik bulguları olan tüm hastalara sicak kompres tedavi denendi. Yedi hastada barsak kanlanma bozukluğunun devam etmesi üzerine ince bağırsak rezeksiyon ve anastomozu yapıldı (rezeksiyon oran $1=\% 43,8$ ). Direkt hernisi olup rezeksiyon yapılan beş hastaya Mc Vay onarım, indirekt hernisi olan iki hastaya ise Bassini onarımı yapıldı. Barsak rezeksiyonu yapılan hastalarda mesh kullanılmadı. Barsak rezeksiyonu yapılmayan dokuz hastaya ise meshli inguinal herni onarımı yapıld. Rezeksiyon yapılan tüm hastalara batın içi dren konuldu. Rezeksiyon yapılmayan üç hastada ise cerrahi loja drenaj katateri konuldu. 
Postoperatif dönemde ince barsak rezeksiyonu yapılan 2 ve yapılmayan 1 hasta olmak üzere toplam 3 hastada atelektazi, rezeksiyon yapılan ve Mc Vay onarım yapılan 2 hastada ise yara yeri enfeksiyonu gelişti. Hastaların ortalama hastanede kalış süreleri 8,21 $\pm 3,78$ (3-15) gündü. Postoperatif 3 hastada mortalite görüldü. $\mathrm{Bu}$ hastaların tamamı ince barsak rezeksiyonu yapılan hastalardı. Üç komorbid hastalığ 1 olan ve genel anestezi altında fitık cerrahisi uygulanan iki hasta pulmoner kaynaklı sepsise bağlı çoklu organ yetmezliği gelişmesi nedeniyle; 1 hasta ise pulmoner emboli gelişmesi nedeniyle ex oldu. Çalışmanın morbidite oranı \%31,2 iken; mortalite oran $1 \% 18,7$ idi.

Tablo 1. İnkarsere inguinal herni nedeniyle opere edilen hastaların klinik özellikleri.

\begin{tabular}{|c|c|}
\hline Klinik Özellik & n (\%) \\
\hline Yaș (ortalama \pm ss) & $88,07 \pm 3,22$ \\
\hline \multicolumn{2}{|l|}{ Cinsiyet } \\
\hline - Erkek & $14(\% 87,5)$ \\
\hline - Kadın & $2(\% 12,5)$ \\
\hline \multicolumn{2}{|l|}{ Komorbid hastalık varlığı } \\
\hline - 1 hastalık & $4(\% 25)$ \\
\hline - $\quad 2$ hastalık & $7(\% 43,7)$ \\
\hline - 3 hastalık & $2(\% 12,5)$ \\
\hline - Hastalık yok & $3(\% 18,8)$ \\
\hline \multicolumn{2}{|l|}{ Fitık tarafi } \\
\hline - Sağ & $12(\% 75)$ \\
\hline - Sol & $4(\% 25)$ \\
\hline \multicolumn{2}{|l|}{ Fitık türü } \\
\hline - Direkt & $6(\% 37,5)$ \\
\hline - İndirekt & $10(\% 62,5)$ \\
\hline \multicolumn{2}{|l|}{ ASA skoru } \\
\hline - ASA 3 & $4(\% 24)$ \\
\hline - $\quad$ ASA 4 & $9(\% 56,2)$ \\
\hline - $\quad$ ASA 5 & $3(\% 19,8)$ \\
\hline \multicolumn{2}{|l|}{ Anestezi tipi } \\
\hline - Genel & $11(\% 68,7)$ \\
\hline - Bölgesel & $5(\% 31,3)$ \\
\hline \multicolumn{2}{|l|}{ Cerrahi tipi } \\
\hline - Meshli tamir & $9(\% 56,2)$ \\
\hline - McVay onarım & $5(\% 31,2)$ \\
\hline - Bassini onarım & $2(\% 12,6)$ \\
\hline \multicolumn{2}{|l|}{ Rezeksiyon } \\
\hline - Var & $7(\% 43,8)$ \\
\hline - Yok & $9(\% 56,2)$ \\
\hline \multicolumn{2}{|l|}{ Morbidite } \\
\hline - $\quad$ Atelektazi & $3(\% 18,7)$ \\
\hline - Yara yeri enfeksiyonu & $2(\% 12,6)$ \\
\hline \multicolumn{2}{|l|}{ Mortalite } \\
\hline - Sepsis & $2(\% 12,6)$ \\
\hline - $\quad$ Pulmoner emboli & $1(\% 6,2)$ \\
\hline Hastane kalış süresi (ortalama \pm ss) & $8,21 \pm 3,78$ \\
\hline
\end{tabular}




\section{Tartışma}

Yaşlı hasta popülasyonunda inguinal herni prevalansı destek dokularda oluşan zayıflık ve karın içi basıncını artıran komorbid hastalıklar nedeniyle artmaktadır. Ayrıca bu hastalarda görülen inguinal hernilerde inkarserasyon riski daha fazla olup; hastanede kalış süresi, morbidite ve mortalite oranları da yüksektir (6). İnkarserasyon oranı erkeklerde inguinal herniler varlığında, kadınlarda ise femoral ve umblikal herni varlığında daha fazladır (7). Primatesta ve ark. yapmış oldukları çalışmada inkarsere inguinal herni nedeniyle acil ameliyat edilen hastaların \%91'inin erkek olduğunu bildirmişlerdir (8). Çalışmamız da literatürle uyumlu olarak hastaların \%87,5'ini erkek hastalar oluşturmaktaydı.

İleri yaşlı hasta grubunda mortalite ve morbidite riskinin yüksek oluşu malnutrisyon, fizyolojik değişiklikler ve yandaş hastalıklar nedeniyledir. İnguinal herni tanısı almış geriatrik hastaların \%75-90'ında eşlik eden yandaş hastalık mevcuttur (9). Literatürde inguinal hernisi olan geriatrik hastalarda en sik olarak KOAH, hipertansiyon ve koroner arter hastalıklarının eşlik ettiği bildirilmiştir (4). Çalışmamızda; hastaların 13'ünde $(\% 81,2)$ yandaş hastalık mevcut olup; bu hastaların 10'unda $(\% 62,5)$ koroner arter hastalığı ile hipertansiyon, 7'sinde $(\% 43,7)$ DM, 6'sinda $(\% 37,5)$ KOAH mevcuttu. İleri yaşlı hasta grubunda inguinal herni cerrahi sonuçlarını incelendiğimiz çalışmamızda eşlik eden yandaş hastalık oranları literatür ile uyumlu olmasına rağmen; eşlik eden $\mathrm{KOAH}$ varlığı çalışmamızda daha düşük oranda saptanmıştır (10).

İleri yaşlı hasta grubunda operatif riskler cerrahları konservatif tedaviye yöneltmiştir. Konservatif izleme alınan hasta sayıs1 arttıça; inkarserasyon oranında artış görülmektedir. Acil şartlarda ameliyat edilen geriatrik hastalarda morbidite ve mortalite oranları ile ASA skor yüksekliği de artmaktadır (11). Literatürde 70 yaş ve üzeri inkarsere inguinal herni nedeniyle yapilan acil cerrahi girişimler sonrasında mortalite oranı \%4-20 olarak rapor edilmektedir. Iş1l ve arkadaşlarının yapmış oldukları çalışmada inkarsere inguinal herni nedeniyle acil cerrahi girişim uygulanan geriatrik hastalarda barsak rezeksiyon oranı $\% 21$ olarak belirtilmiştir (10). Çalışmamızda hastaların 7'sine $(\% 43,8)$ nekrotik görünüm nedeniyle barsak rezeksiyonu yapılmış ve mortalite oranı \%18,7 olarak bulunmuştur. Mortalite görülen tüm hastalar, barsak rezeksiyonu yapilan olgulardan oluşmaktaydı.

Son dönemlerde anestezi alanındaki gelişmelere bağlı olarak etkin preoperatif anestezi ve risk değerlendirmesi ile postoperatif daha iyi sonuçlar alınabilmektedir. Opere edilen hastaların ASA skor değerlendirmesinde 4 hastada ASA III (\%25), 9 hastada ASA IV $(\% 56,2)$ ve 3 hasta da ASA V $(\% 18,8)$ şeklinde olduğu görüldü. 65 yaş üstü hastaların dahil edildiği bir diğer çalışmada ise acil cerrahi uygulanan geriatrik yaş hastaların \%61'i ASA IV ve \%5'i ASA V olarak bulunmuştur (10).

İnkarsere inguinal herni olgularında diğer önemli bir sorun seçilecek cerrahi yöntemdir. Cerrahi yöntem seçiminde en önemli etken barsak rezeksiyon varlığ 1 ve cerrahi lojda gastrointestinal sistem içeriği varlığıdır. Literatürde fitık onarımından sonra \%8'lere varan mesh nedenli enfeksiyon vakaları bildirilmiştir (12). Çalışmalar, komplike olmayan olgularda dikiş onarım tekniği (mesh kullanılmadan) ve mesh kullanılan vakalar arasında enfeksiyon insidansında önemli bir fark olmadığını göstermiştir $(13,14)$. Fakat inkarserasyon nedeniyle perforasyon gelişen komplike olgularda fittk tamirinde mesh kullanımı önerilmemektedir. $\mathrm{Bu}$ olgularda mesh kullanılması yüzeyel, derin cerrahi yeri enfeksiyonu ile meshoma gibi daha komplike cerrahi alan enfeksiyonları gelişime neden olabilmektedir (15). Çalışmamızda barsak rezeksiyonu nedeniyle mesh kullanılmadan onarım yapilan 2 hastada postoperatif dönemde yara yeri enfeksiyonu gelişmiştir.

İleri yaş hasta popülasyonu cerrahi strese ve metabolik bozukluklara karşı daha frajildir (6). İleri yaş hastalarda postoperatif komplikasyon ve hastanede kalış sürelerinde de artış görülmektedir (16). Geriatrik hastalarda inguinal herni ameliyatlarında hastane kalış süresini inceleyen bir çalışmada; elektif cerrahi sonrası hastanede kalış süresi 
1,3 gün, acil cerrahi sonras1 7,9 gün olarak bildirilmiştir (10). Çalışmamızda ortalama hastanede kalış süresi 8,21 gün (3-15 gün) olarak görülmüştür.

Sonuç olarak komorbid faktörler ve yüksek ASA skoruna sahip ileri geriatrik hastalar, uygun teknik, uygun postoperatif yoğun bakım koşulları ve yeterli preoperatif hazırlıklar yapılarak elektif koşullarda inguinal herni tamiri için ameliyat olabilir.
Aksi takdirde, acil durumlarda yapilan ameliyatlarda barsak rezeksiyon oranıyla birlikte, morbidite ve mortalite oranları da artmaktadır. İleri yaş ve ASA yüksekliğinin, ameliyatı ertelemek için sebep olmaması gerektiğini ve bu hasta grubunda olası bir acil ameliyatın risklerinden kurtulmak için elektif şartlarda ameliyat edilmesini öneriyoruz.

\subsubsection{1 tarihinde 8.Ulusal Fitık Kongresi'nde} (e-kongre) sözlü bildiri olarak sunulmuştur.

\section{KAYNAKLAR}

1. https://www.nufusu.com/turkiye-nufusu-yasgruplari [Erișim zamanı: 01/04/2021].

2. https://www.who.int/ageing/publications/global_h ealth.pdf [Erișim zaman1: 01/04/2021].

3. Matsuo M, Tazawa K. Reference range of clinical blood tests in physically independent patients of advanced age with groin hernia in a Japanese hospital. Geriatr Gerontol Int. 2019;19:780-85.

4. Yang W, Tao Z, Chen H, Li Q, Chu PG, Yen Y, et al. Amyand's hernia in elderly patients: diagnostic, anesthetic, and perioperative considerations. J Invest Surg. 2009;22:426-9.

5. Kulacoglu H, Polat A, Moran M, Gök R, Coşkun F. Elective inguinal hernia repair in the elderly. TurkishJournal of Geriatrics. 2000;3:64-8.

6. Kartal A, Çitgez B, Besler E, Yetkin SG, Uludağ M, Akgün İE, et al. İnkarsere inguinal hernilerde deneyimimiz. Ş EEAH Tıp Bülteni 2014; 48: 287.

7. Ischer D, Renoult C, Gold B, Mégevand JM. La hernie fémorale chez la personne âgée [Femoral hernia in geriatric patient]. Rev Med Suisse. 2018 Jan 31;14:279-282.

8. Primatesta $\mathrm{P}$, Goldacre MJ. Inguinal hernia repair: incidence of elective and emergency surgery, readmission and mortality. International journal of epidemiology. 1996;25:835-9.

9. Fang Z, Ren F, Zhou J, Tian J. Biologic mesh versus synthetic mesh in open inguinal hernia repair: system review and meta-analysis. ANZ J Surg. 2015;85:910-6.

10. Iş11 RG, Demir U, Kaya C, Bostancı Ö, İdiz UO, Işıl CT, et al. Approach to inguinal hernia in highrisk geriatric patients: Should it be elective or emergent? Turkish Journal of Trauma and Emergency Surgery, 2017: 23:122-27.

11. Elhage SA, Shao JM, Deerenberg EB, Prasad T, Colavita PD, Kercher KW, et al. Laparoscopic Ventral Hernia Repair in the Geriatric Population : An Assessment of Long-Term Outcomes and Quality of Life. Am Surg. 2020;86:1015-21.

12. Heniford BT, Park A, Ramshaw BJ, Voeller G. Laparoscopic ventral and incisional hernia repair in 407 patients. J Am Coll Surg 2000; 190: 64550.

13. Arroyo A, Garcia P, Perez F, Andreu J, Candela F, Calpena R. Randomized clinical trial comparing suture and mesh repair of umbilical hernia in adults. Br J Surg 2001; 88: 1321-23.

14. Grant AM. Open mesh versus non-mesh repair of groin hernia: meta-analysis of randomised trials based on individual patient data [corrected]. Hernia 2002; 6: 130-36.

15. Kalaycı T, Iliklerden UH. A rare case mimicking abdominal wall neoplasms: Meshoma. Turkiye Klinikleri J Case Rep. 2020;28:220-3.

16. Isil RG, Yazici P, Demir U, Kaya C, Bostanci O, Idiz UO, et al. Outcomes of geriatric patients who underwent incarcerated inguinal hernia repair. Şişli Etfal Tip Bülteni 2016;50:103-109. 